\title{
OS LUGARES DA MULHER NEGRA NA PUBLICIDADE BRASILEIRA
}


Resumo: Na sociedade pós-moderna, a publicidade ocupa um espaço de grande importância e influência. Ela modela atitudes e comportamentos do mundo contemporâneo. O presente artigo objetiva discutir como se estrutura a participação das mulheres negras neste meio de comunicação. Este estudo lança um olhar histórico sobre a presença dos negros em anúncios publicitários de épocas distintas, a fim de uma reflexão sobre a inserção da afrodescendente na publicidade de hoje.

Palavras chave: publicidade; mulheres negras; identidades negras

\section{LAS UBICACIONES DE LA MUJER NEGRA EN LA PUBLICIDAD BRASILEÑA}

Resumen: En la sociedad posmoderna, la publicidad tiene un espacio de gran importancia e influencia. Ella determina actitudes y comportamientos del mundo contemporáneo. El presente artículo objetiva discutir como se estructura la participación de las mujeres negras en esto medio de comunicación. Este estudio muestra una mirada histórica a cerca de la presencia de los negros en anuncios publicitarios de periodos distintos, con la finalidad de una reflexión sobre la inserción de la afrodescendiente en la publicidad de hoy.

Palabras clave: publicidad; mujeres negras; identidades negras

THE PLACES OF BLACK WOMEN IN BRAZILIAN ADVERTISING

Abstract: In postmodern society, advertising occupies an area of great importance and influence. It shapes attitudes and behaviors of the contemporary world. This article discusses the participation of black women in the media. This study takes a historical look about the presence of black people in advertisements on different times in order to reflect about the inclusion of black woman in advertisement today.

Keywords: advertising; black womens; black identities 


\section{INTRODUÇÃO: ESTEREÓTIPOS SECULARES}

Ao final do século XVIII, em 1789, em Eastern Cape, África do Sul, nasceu Saartje (ou Sara) Baartman conhecida como Vênus Hotentote. Ela representa o primeiro exemplar que define o corpo da mulher negra. Borges (2012, p. 190) explica que como era comum em mulheres hotentotes, Sarah tinha nádegas proeminentes (esteatopigia) e grandes lábios hipertrofiados, em virtude da manipulação da genitália (símbolo de beleza para os hotentotes e bosquímanos), o que lhe rendeu o apelido de tablier; avental em francês.

Essas características que a diferenciavam despertou a atenção coletiva de viajantes europeus, responsáveis por converterem Sarah em espetáculo público. O espanto, a atração e a repulsa pelo anormal, pelo disforme constituíram uma nova ordem de coisas que passavam a despertar interesse de colecionadores, constituindo-se no que Hall (1997, p. 264) define como "fetichismo e rejeição" em relação ao negro. O corpo de Sarah servia para confirmar a normalidade e civilidade européia. Pelos outros deformados, anormais, estranhos, risíveis, o eu civilizado confirmava a sua retidão, normalidade, oferecendo um padrão universal de homem, ressalta Borges (2012, p. 192).

No Brasil, após a independência em 1822, houve um despertar para a necessidade da construção de uma identidade nacional que se representasse como civilizada. Paralelamente a isso, havia um grande contingente de negros recém-libertos pela Lei Áurea, que estavam ganhando espaço nas zonas urbanas. Nesse contexto, as elites nacionais pautaram-se em teorias racialistas para criar uma imagem do país sem a presença do negro. Tais teorias difundiam a inferioridade da etnia negra, apresentando-a como animalesca e incivilizada. Neste cenário preconceituoso e excludente, restaram ao negro, as posições mais subalternas da sociedade. Segundo Sodré (1999, p. 85) "as teorias raciais transformavam-se em ferramentas para a invenção de uma identidade nacional". Diante do cenário nacional do período, se desenvolveu o processo de embranquecimento da nação brasileira. Visando promover a tal imagem "civilizada e culta" do país, as elites da época incentivaram a imigração de trabalhadores europeus para o Brasil. Os imigrantes ajudariam no processo de branqueamento da população brasileira.

1 Tradução do livro do inglês: "fetishism and disavowal" 
As teorias racialistas que orientam projetos de nação nos tempos de Brasil Império, apesar de ultrapassadas no continente europeu, continuaram em voga nos primeiros anos do Brasil República. Assim, ao lado do avanço e econômico e da necessidade de instituições modernas, o aprimoramento racial da população persistia como fator determinante do progresso da nação. (MARTINS, 2009, p.31)

Ao mesmo tempo, a imagem do negro foi bestializada, associada a atraso e degradação social. O bandido, o degenerado, o vagabundo, o sujo e o bruxo foram apenas alguns dos estereótipos vinculados aos ex-escravos. Foi assim que a identidade nacional, e consequentemente a imagem do negro, foi estrategicamente planejada pelas elites brasileiras. Este processo identitário demarcou diferenças entre os sujeitos da sociedade. Importante ressaltar que os estereótipos ainda estão, mesmo que subjetivamente e veladamente, presentes em nossa sociedade, por vezes transformando-se e adaptando-se.

São os resíduos do passado que ainda permanecem segundo Raymond Williams (1979). Conforme o autor, o residual por definição, foi efetivamente formado no passado, mas ainda está ativo no processo cultural, não só como um elemento do passado, mas como um elemento efetivo do presente. Williams explica que, em certos pontos, a cultura dominante não pode permitir demasiada experiência e prática residuais fora de si mesma, pelo menos sem um risco. É pela incorporação daquilo que é inevitavelmente residual - pela interpretação, diluição, projeção e inclusão e exclusão discriminativas - que o trabalho de tradição seletiva se faz especialmente evidente e é mantido.

Com relação à estereotipização, é possível observar que ela tem reflexo nos produtos midiáticos, sendo propagada, em muitos casos, pelo mercado publicitário. Ramos (2002, p. 9) considera que:

Discutir as dinâmicas da mídia frente às questões de raça e etnicidade é, em grande medida, discutir as matrizes do racismo no Brasil. Os meios de comunicação são, por assim dizer, um caso modelo de representação das nossas relações sociais.

Sendo assim, é preciso entender a mídia como uma das entidades que produzem subjetividades, assim como tantas outras, como a família, a igreja e a universidade. O diferencial da mídia para as demais entidades reside na potência e alcance das subjetividades produzidas. A esfera midiática atravessa todas as outras esferas, através de seus mais variados produtos, como os produzidos pela publicidade. 


\section{DE PRODUTO A CONSUMIDOR}

Assim como em diversos países, no Brasil, a publicidade sempre andou de mãos dadas com o desenvolvimento do capitalismo. Aliás, esta atividade teve inicio em terras brasileiras no século XIX. Neste período, o crescimento da economia promoveu um aumento populacional nas áreas urbanas, que comportava variados setores nacionais que necessitavam comunicar sua existência ao mercado. Na busca de um quadro comum de referências, a mídia institui padrões operacionais: falas e sotaques, vestimentas, modelos de beleza, modos específicos de escrever, filmar e fotografar, estabelecendo sempre modelos e estilos de vida a serem seguidos (BORGES, 2012).

Os primeiros anúncios publicitários se referiam a ofertas de serviços de artesãos e profissionais liberais, vendas de imóveis, e também venda de escravos. Principal fonte de renda dos periódicos da época, os anúncios eram abundantes, chegando a dividir, e até mesmo a superar o espaço destinado aos editoriais e às notícias. (SCHWARCZ, 2001).

Anos se passaram e o negro continuou sendo mostrado como produto nos jornais brasileiros da época. Porém, após a Lei Eusébio de Queiroz, de 1850 que proibiu o tráfico de escravos realizado no Oceano Atlântico em sentido ao Brasil - o negro deixou de ser anunciado em operações de compra e venda para ser retratado como fugitivo.

A partir do momento em que o negro deixa de ser escravizado, ele passa a ser consumidor, compõe o público alvo dos vendedores. Entretanto, já em condição de liberdade, na primeira metade do século XX, o negro raramente aparecia em anúncios publicitários, e quando aparecia, estava em uma posição de inferioridade social. Resumindo: papel do negro era o da invisibilidade.

Durante décadas, a publicidade, assim como outros setores da mídia, continuou menosprezando a existência dos negros. Em 1944, Abdias Nascimento fundou o Teatro Experimental do Negro (TEN), com o objetivo de valorizar o negro e sua cultura através da dramaturgia. A veterana atriz Ruth de Souza participou dos primeiros momentos do TEN. Outro espaço importante para os afrodescendentes veio em 1984, quando a atriz Zezé Mota criou o Centro de Informação e Documentação do Artista Negro (Cidan). O intuito era promover a inserção de artistas negros no mercado artístico. A iniciativa da atriz teve grande importância, mas a situação do negro na mídia não era uma problemática tão fácil de resolver. Até porque, “em pleno ano de 1988 via-se a Expedita, 
de cor negra e na condição de empregada inserida no comercial do leite condensado Glória; mas não havia anúncios de mulheres negras como gerentes de banco ou comprando seguro de carro". (GIACOMINI, 1991, p. 61).

Os publicitários dessa época alegavam que para serem eficientes, os discursos das propagandas deveriam provocar projeções identitárias positivas nos consumidores. Nesse momento, predominava no país, o padrão da beleza européia, a preferência era por pessoas louras e com olhos claros. Logo, para as empresas publicitárias brasileiras, colocar artistas negros em seus comerciais significava pôr em risco a empatia do produto junto aos consumidores. A publicidade até podia enxergar o negro como consumidor de produtos, mas não o queria como modelo em frente às câmaras. Para Lopes (2007, p. 176):

E a publicidade, que dá suporte financeiro às produções televisivas, insiste em não associar à imagem do povo negro os produtos que anuncia mesmo aqueles sabidamente consumidos pelos afro-brasileiros em geral. Daí, o dilema, da jovem negra que se acha feia por não ser parecida com as modelos dos anúncios, pois não tem a mesma pele clara, nem mesmo os cabelos louros e sedosos. E muito pior, daí também, o drama das menininhas que, na fantasia maternal de sua infância, são obrigadas a embalar em seus colinhos as bonecas louras e rosadas de sempre.

A carência de espaço para o negro nos meios de comunicação também podia ser constatada na televisão brasileira. Os atores afrodescendentes tinham pouco espaço nas telenovelas e na programação televisiva em geral. Assim como as campanhas publicitárias, a televisão também colaborou para a propagação de estereótipos negativos vinculados aos negros. Alguns autores até tentaram dar lugar a relacionamentos interraciais em suas novelas, mas a rejeição dos telespectadores era enorme. (RECH, 2003).

A TV, o teatro, o cinema e a publicidade, entre outras mídias, têm sido extremamente eficientes em vender, tanto para o exterior quanto internamente, a ideia de que o Brasil é um país de pessoas brancas (quando não louras), mesmo que, eventualmente, surja um negro subordinado em algum canto da tela ou no fundo de uma foto.

Na publicidade, era possível ver a mulher negra como a empregada doméstica, que ajudava a patroa a comprar determinado produto para a limpeza ou para a alimentação. Também era possível ver o homem negro como o jardineiro da casa de pessoas brancas. Mas, raramente o afrodescendente era apresen- 
tado em situação de igualdade com branco. Ainda nos anos 1980, já existiam produtos destinados especificamente aos negros. Porém, os anúncios destes produtos acabavam por reforçar preconceitos em relação aos afro-brasileiros. Um exemplo é o anúncio da Hené, que torna liso e "bom" o cabelo crespo e "ruim". Gino Giacomini (1991, p. 61), ressalta que apesar de muitas pessoas perceberam que a publicidade da época eliminava e estereotipava os negros, pouco se discutia a questão.

O impacto da publicidade nos diferentes grupos étnicos brasileiros não tem recebido grande espaço nas discussões do setor, mas são visíveis certas distorções em anúncios que, via de regra, valorizam a etnia branca em relação às outras.

Desse modo, a invisibilidade e deturpação da imagem de mulheres e homens negros na publicidade eram assuntos praticamente intocáveis, velados. A década de 1980 passou sem consideráveis mudanças no que diz respeito à inclusão e valorização do negro na mídia de forma geral. Produções televisivas e materiais impressos da época teimavam em esconder os afrodescendentes dos receptores. $O$ espaço aos negros tendia a aumentar durante eventos com data marcada, como o carnaval e em eventos esportivos.

\section{NA VALORIZAÇÃO DA BELEZA, SURGE A IDENTIDADE NEGRA}

Na década de 1990, nasceu uma revista voltada especialmente para o público negro. Em 1996, é lançada a revista Raça, que foi um êxito de vendas nas suas primeiras edições. Hoje, a revista possui vendas menos expressivas, mas ainda atrai interesse de leitores negros. A Raça conseguiu influenciar o comportamento do mercado publicitário, que passou a incluir e valorizar mais o negro em peças publicitárias. Castro (2010, p. 106) faz considerações sobre o papel da publicação:

Foi esta discussão que nos fez perceber que, em Raça Brasil, o negro e a negra estão sempre bem vestidos, sempre bem penteados e sempre bem maquiados, por mais que se fale em problemas de periferia, de quilombo ou de favela. O homem e a mulher negros de periferia podem obter ascensão social, dignidade, fama e dinheiro sem que precisem adentrar o mundo do crime. 
Este período em que a revista foi lançada coincidiu com o momento em que o negro passou a ser considerado consumidor ativo. "Nesse contexto, houve também inclusão de um maior número de negros em outros produtos culturais, como telejornalismo, programa de auditório, telenovelas e outros" (SANTOS, 2004, p.10). Uma das características mais destacáveis na revista Raça é o orgulho pelos traços estéticos do afrodescendente. A identidade do negro na publicidade brasileira está diretamente conectada à valorização da sua beleza em anúncios publicitários.

No caso da "raça" e do mercado no Brasil, é particularmente interessante o fato de que os produtos específicos destinados a pessoas de cor são, quase todos, os que pretendem embelezar. São específicos para o fenótipo, a aparência. É como se a própria "aparência" se tornasse (ou esteja se tornando) o ícone da identidade negra no Brasil, levando muita gente, que de outra forma se considera morena, mulata etc., a considerar-se também “negra”. (FRY, 2005, p. 254)

A visibilidade dos afrodescendentes na publicidade também tem relação direta com as lutas do movimento negro. Fato também é, que o negro, mesmo que timidamente, começou a ascender socialmente no fim do século XX. A classe média negra despertou o interesse das grandes empresas publicitárias. Na segunda metade dos anos 1990, foi crescente o número de anúncios que tinham a etnia negra como público alvo. Hoje, há produtos destinados especificamente aos negros, e em especial na linha dos cosméticos, marcas famosas utilizam negros para estrelarem campanhas massivamente divulgadas.

Após as conquistas dos movimentos e manifestações que têm como objetivo a igualdade e luta contra o preconceito e discriminações raciais, verificamos a ampliação de um mercado direcionado aos afrodescendentes, que tem atraído muitos investimentos e capital. De certa forma, é necessário que os negros se identifiquem com os produtos que irão comprar, especialmente se trazem imagens que possibilitam isso; porém não se deve descartar a ideia de que o mercado se aproveitou deste momento para lucrar com uma discussão em desenvolvimento. (COUTINHO, 2011, p. 8)

Notavelmente, nos últimos anos, a publicidade brasileira teve avanços em relação à inserção do negro em materiais produzidos pela publicidade. Sobretudo, é necessário avaliar de que forma esses avanços aconteceram. Mais 
do que isso, é importante compreender todos os valores e interesses que estão em jogo no discurso das empresas que passaram a incluir mais negros em suas campanhas.

\section{MULHERES NEGRAS NOS ESPAÇOS PUBLICITÁRIOS}

Ser negra no Brasil é estar inserida num ciclo de marginalização e discriminação social. Mulheres afrodescendentes costumam sofrer duplo preconceito: racial e de gênero. Se a mulher negra for pobre, o caso se agrava ainda mais. A herança do período escravocrata disseminou um juízo preconceituoso, que reserva para a afrodescendente, trabalhos domésticos ou que exploram o corpo. Assim como em qualquer campo social, nos meios de comunicação, dentre eles a publicidade, a mulher negra precisa comprovar competência mais vezes do que a mulher branca.

Nos anos 1990, a britânica Naomi Campbell se destacou como uma das modelos mais requisitadas no mundo da moda. O sucesso de Naomi influenciou agências de moda de vários países, inclusive no Brasil, a investir no potencial de modelos negros. Na mesma década, mais precisamente em 1996, a Rede Manchete levou ao ar Xica da Silva, primeira telenovela brasileira em que a protagonista era uma atriz negra. Taís Araújo deu vida à personagem título. Ela obteve grande sucesso, sendo um dos rostos nos quais a publicidade da época mais investiu. Em 2004, na Rede Globo, a atriz interpretou a primeira protagonista negra em uma telenovela da emissora - Da Cor do Pecado - , e em 2010, a atriz deu vida a Helena, de Viver a Vida, primeira telenovela do horário nobre que trouxe uma afrodescendente no papel principal. O sucesso na televisão refletiu-se em diversas campanhas publicitárias estreladas pela atriz. A popularidade e reconhecimento de Taís é um caso raro entre atrizes negras que atuam na televisão, já que estas raramente são escaladas para papéis de destaque em produções televisivas. Podemos citar também, a afrodescendente Camila Pitanga. A atriz já interpretou protagonistas em novelas da Rede Globo e é uma das queridinhas do mercado publicitário. O sucesso de Camila entre os anunciantes é tão grande, que de janeiro a julho de 2012, ela foi o rosto que mais apareceu em comerciais na televisão aberta (Figura 1), ultrapassando celebridades como Reynaldo Gianecchini e Michel Teló. 


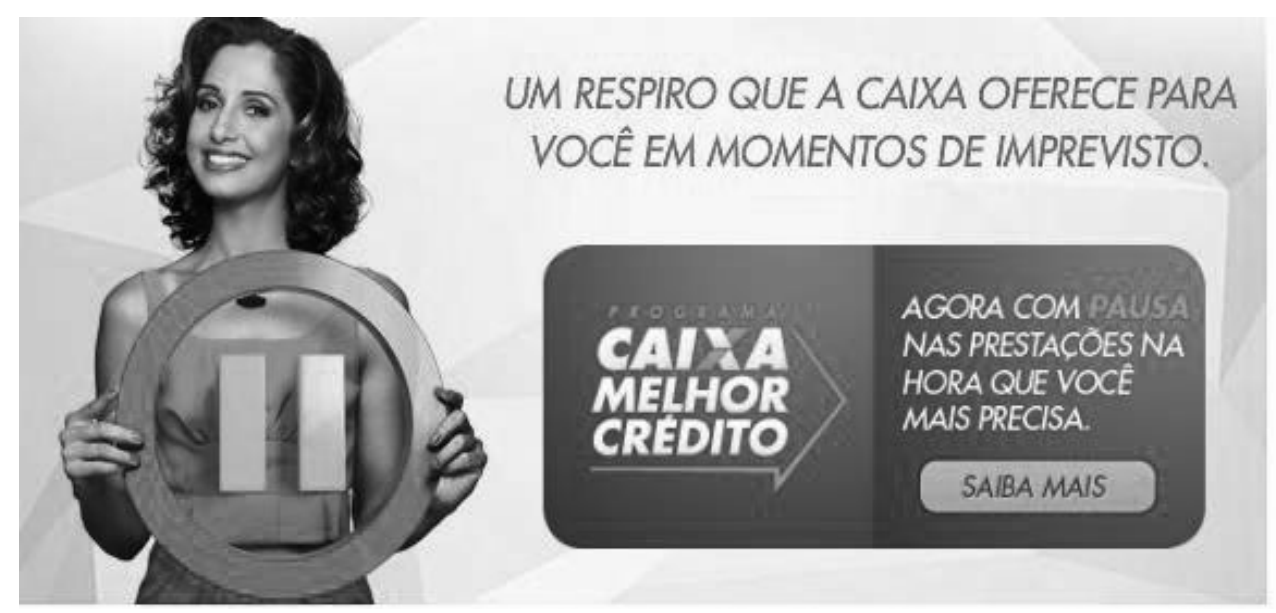

Figura 1 - Camila Pitanga em anúncio da Caixa, em 2012

A baixa quantidade de atrizes negras em papéis de destaque na televisão, bem como em campanhas publicitárias, realmente era ainda mais explícito em décadas anteriores. Quando modelos negras apareciam em editoriais de moda, na maioria das vezes, eram colocadas por estratégias específicas. Bonadio (2009), em estudo sobre a participação de modelos negras em editoriais de moda, reportagens e anúncios impressos na década de 1960, observou que em um dos casos, a presença da modelo negra tinha vinculação direta ao futebol, mais precisamente à seleção brasileira da época. A associação da modelo negra a jogadores negros de sucesso foi uma estratégia publicitária, que não visava incluir modelos afrodescendentes no meio artístico, muito menos social, mas sim fazer menção ao sucesso de Pelé e de tantos outros atletas negros do período.

Como ressalta a autora em seu estudo, na década de 1960, o padrão de beleza da mulher excluía os traços africanos. Colocar uma modelo negra entre modelos brancas era uma tarefa ousada e arriscada para a época. Devemos considerar que durante esta década, modelos negras passaram a estampar capas de revistas de moda internacional (figura 2). Donyale Luna foi a primeira modelo negra a aparecer na capa de uma grande publicação americana. Era a edição de janeiro de 1965 da Harper's Bazaar. 


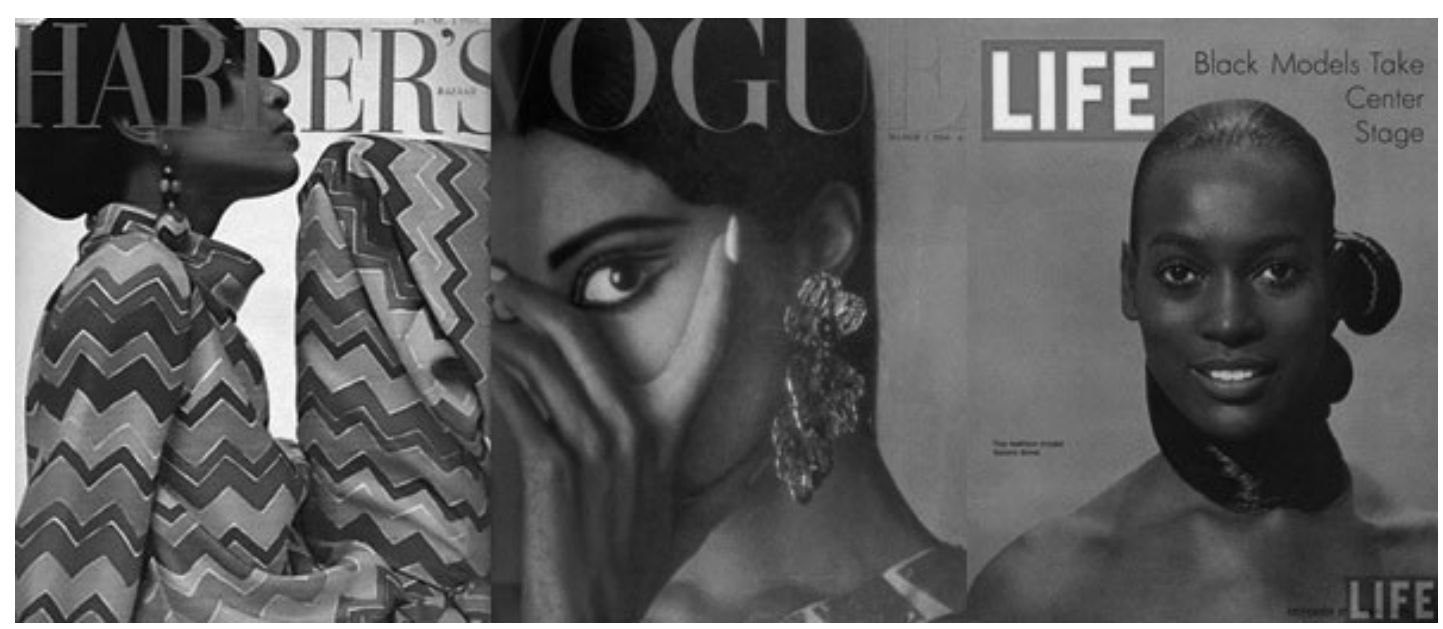

Figura 2 - Da direita para a esquerda: Donyale Luna na Harper's Bazaar (1965). Novamente Donyale, na Vogue (1966). E Naomi Sims na Life (1969)

O novo cenário internacional da moda influenciou diretamente as publicações brasileiras. Mas, ainda hoje, as afrodescendentes são minorias em editoriais de moda por aqui. E assim como ainda sobrevive aquela publicidade que vincula modelos negras ao esporte brasileiro, também há aquela que traz como protagonistas, mesmo que raramente, as próprias atletas negras. Em 2010, a campeã mundial de ginástica artística, Daiane dos Santos, estrelou campanha da marca de arroz Alibabá (figura 3). Mesmo com inúmeras esportistas negras brasileiras - em modalidades variadas, como: atletismo, futebol e vôlei - poucas atletas afrodescendentes estrelam campanhas publicitárias. A situação tende a ter leve melhora em períodos de eventos esportivos com grande audiência. Fazendo uma breve análise de imagem, podemos observar que participação de Daiane no anúncio da marca de arroz é estruturada pela noção da brasilidade. A peça explora o verde e o amarelo, inclusive traz a ilustração da bandeira nacional.

O próprio produto ofertado, o arroz, se caracteriza por ser um dos alimentos mais consumidos no dia a dia pelos brasileiros. Portanto, há uma associação da brasilidade que Daiane representa com o caráter popular do produto, e também com a construção visual da peça. Observando este anúncio, podemos considerar ainda, a questão do fenótipo. Quanto mais traços brancos, a modelo, atriz ou atleta negra possuir, mais chances ela terá de ser convidada a estrelar uma campanha publicitária relacionada a temas como estética e beleza. Nesse contexto, mesmo Daiane sendo uma esportista famosa, certas marcas dificilmente iriam convidá-la para promover seus produtos. A própria produção 
da publicidade mostra que, quanto mais escura for a pele de uma mulher negra, mais improváveis são as chances dela se destacar na mídia em geral.

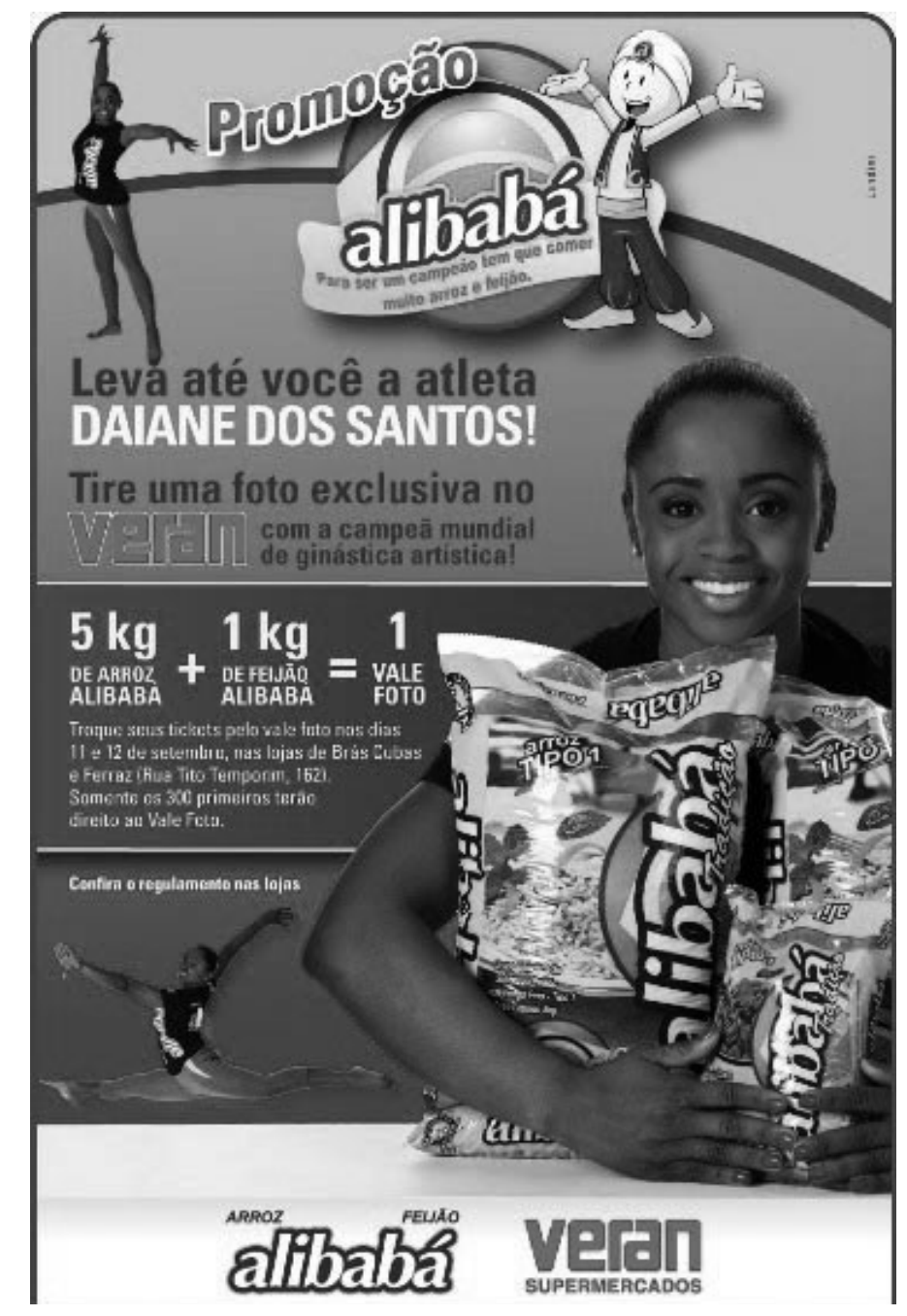

Figura 3 - A atleta Daiane dos Santos como garota propaganda da marca de arroz Alibabá

Quando a publicidade une o estereótipo racial com o sexual e o social, o resultado se torna deturpador. Foi o que aconteceu no anúncio da linha de lingeries Du Loren. Com o cenário de uma favela, a peça apresenta uma mulher negra em trajes íntimos, e a seguinte frase: Pacificar foi fácil. Quero ver dominar. A peça foi proibida de ser exibida pelo Conselho Nacional de Autorregulamentação (CONAR), no mesmo ano em que foi lançada, em 2012. No ano anterior, o CONAR considerou racista e sexista o anúncio da marca de cerveja Devassa. Neste anuncio, a ilustração de uma negra, vinha acompanhado da frase: É pelo corpo que se reconhece a verdadeira negra. Devassa negra encorpada. Estilo dark ale de alta fermentação. Cremosa com aroma de malte torrado. Afrodescendentes poucas vezes protagonizam campanhas publicitárias, e quando isso acon- 
tece, na maioria dos casos, são anúncios recheados de crenças exageradas e equivocadas. Em exemplos como estes, a publicidade insiste em retratar a muIher negra com um ser promíscuo e apelativo. Além do forte apelo erótico, o anúncio da Du Loren ainda reforça o imaginário da mulher da favela, a negra.

A propaganda não é revolucionária, ela vive de clichês sociais, dos preconceitos, só mostrando aquilo que as pessoas querem ver. Nos comerciais, as pessoas querem se ver representadas, numa verdadeira projeção psicanalítica, como lindas, ricas, poderosas. E os pretos são pobres meu amor (PIRES, 1988, P.15).

A publicidade tem o poder de massificar e disseminar ideais históricos preconceituosos. O mercado publicitário tende a se inserir numa perspectiva social que atende interesses do senso comum, pois, trabalha com os mesmos referenciais. Constantemente coloca a mulher de pele escura em segundo plano, omite sua existência e também a apresenta em posições estereotipadas. Usar uma mulher negra como figura central da peça não significa representar a realidade de um espaço social brasileiro. Portanto, o anúncio não contribui para a ruptura de velhos preconceitos, segue o senso comum.

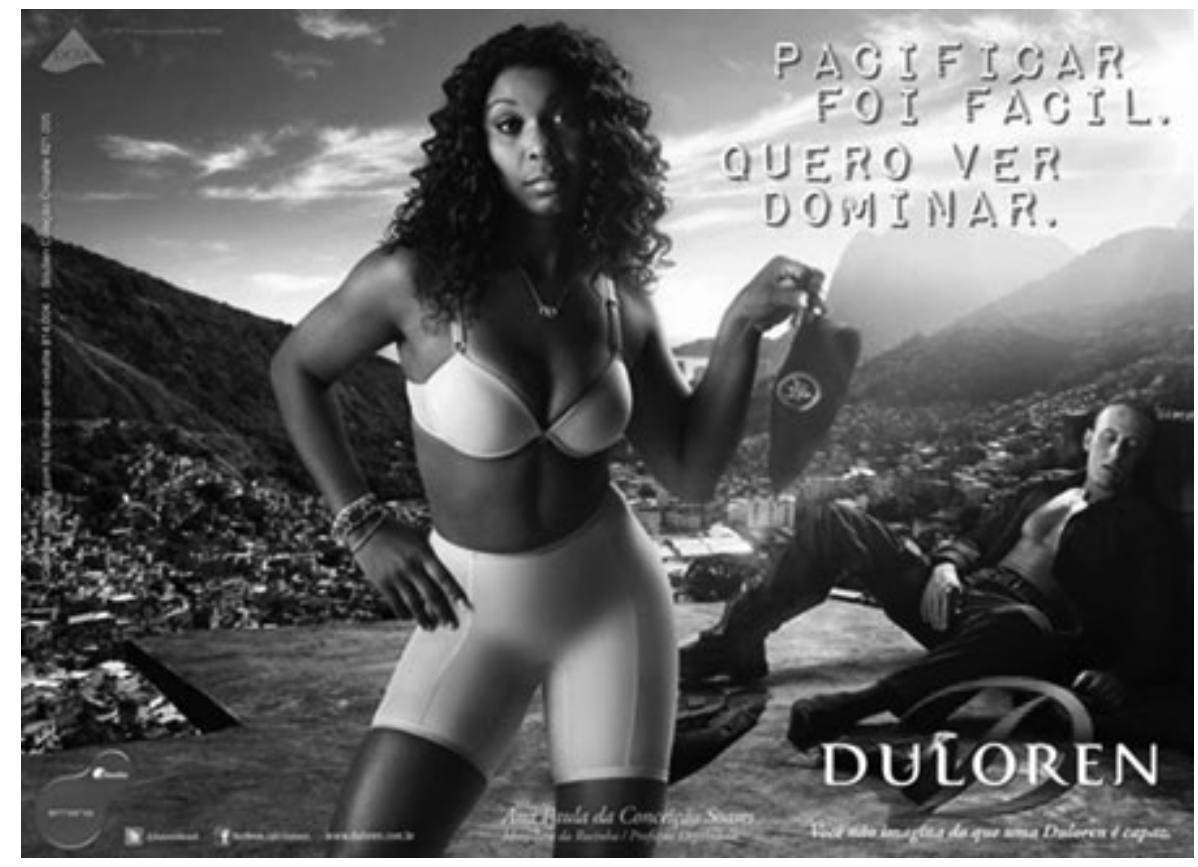

Figura 4 - Modelo negra em anúncio da marca de lingerie Du Loren, 2012

Mulheres negras têm lutado para alcançar uma melhor posição social, e para isso é necessário um esforço gigantesco. A valorização do corpo da mu- 
Iher negra é ofuscada por contornos estereotipados e pensamentos historicamente limitados. A dignidade e o reconhecimento do intelecto da mulher negra são descartados em campanhas como a da Du Loren. Visivelmente, a função de objeto sexual, de entretenimento e diversão da mulher negra ainda é a imagem que alguns publicitários optam em transmitir. Tal opção parece não considerar o contexto sócio-político que as afrodescendentes estão inseridas no Brasil. $O$ anúncio que põe a mulher negra como dominadora de uma situação, e que foi ambientado em uma favela carioca, não leva em conta o fato de que as mulheres negras são as maiores vítimas da violência no Rio de Janeiro.

E são justamente campanhas, como a Basta de Violência contra a Mulher (figura 5), que inserem as afrodescendentes mais expressivamente. São espaços publicitários que recorrem à figura da mulher negra para representá-las, muitas vezes, como vítimas do sistema social, como seres carentes, que necessitam de alguma assistência governamental. Negras aparecem frequentemente em cartazes de programas do governo como: Bolsa Família e Minha Casa, Minha Vida.

O negro, visto pela publicidade como o objeto principal dessa "assistência", é sempre dependente da iniciativa pública ou privada. Na maioria desses anúncios, o negro não tem posição ativa, ele parece não ter qualquer poder sobre aquilo que acontece na sua vida. (CORRÊA, 2006, p. 74).

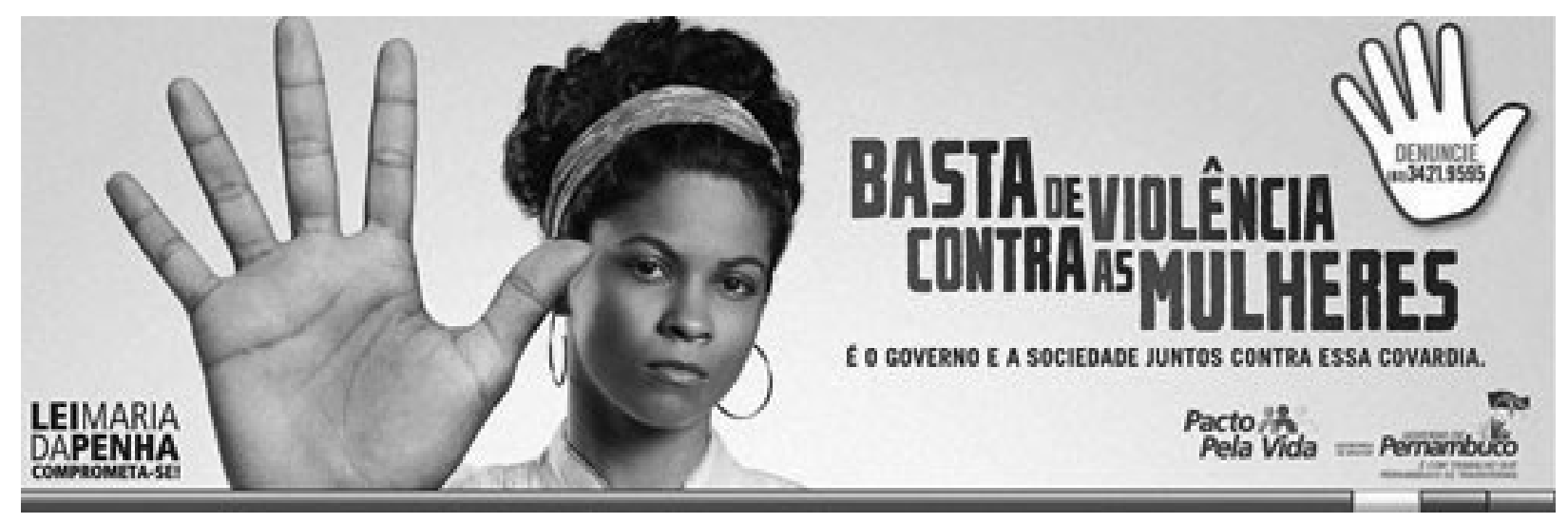

Figura 5 - Modelo negra em campanha contra a violência a mulher, 2011.

Em campanhas de cunho assistencialista, podemos observar a presença de mulheres negras idosas. Mesmo que a inclusão de afrodescendentes dessa faixa-etária não seja uma constante nesse tipo de publicidade, é perceptível a superioridade quantitativa em relação às campanhas de caráter mercadológico, que raramente trazem mulheres negras idosas. 
CADERNOS DE COMUNICAÇÃO (V.16, N.2, JUL-DEZ 2012)

\section{DESNATURALIZANDO AS DIFERENÇAS, DESCONSTRUINDO ESTEREÓTIPOS}

Stuart Hall (1997) nos inquieta com algumas questões, justamente num mundo globalizado onde o discurso da pluralidade e do respeito à diversidade está em pauta e inúmeras ações são empreendidas para tentar reverter esta situação que ainda permanece.

Pode um regime dominante de representação ser desafiado ou modificado? Podem formas 'negativas' de representação, da diferença racial, que abundam em inúmeros exemplos nas mídias, ser revertidos por uma estratégia positiva?² (HALL, 1997, p. 269-270)

Ao pensar na palavra "estereótipo" pode-se verificar que se trata de uma expressão bastante atual, que persiste ao longo dos séculos, e ainda no século XXI, podendo-se citar inúmeros exemplos de como a mídia ainda representa homens e mulheres negras. Exemplo disso é o racismo explícito no programa televisivo "Zorra Total” da Rede Globo (2012), que utiliza um ator que pinta a cara de preto e ridiculariza as mulheres negras (feias, desdentadas, ignorantes, fazendo referências pejorativas aos cabelos dos negros), ou até mesmo de forma "cômica", como os atores Muçum, Tião Macalé, que sempre representaram personagens associados ao alcoolismo, à preguiça, à falta de cultura e de inteligência, o que Hall (1997, p.257) ao falar dos estereótipos como prática significante define como "regime racializado de representação3".

Nesse sentido, acredita-se que é possível “desnaturalizar” a diferença, já que segundo Hall (1997, p.228) os significados "flutuam", não podem ser definitivamente estabelecidos ${ }^{4}$. Assim, segundo o autor não existe um único significado verdadeiro para esta ou aquela imagem, em vez de questionar um significado "certo" ou “errado", o que precisamos perguntar é (Hall, 1997, p.228), “qual o significado

\footnotetext{
2 Tradução do livro do inglês: Can a dominant regime of representation be challenged? What are the counter-strategies which can begin to subvert the representation process? Can 'negative' ways of representing racial difference, which abound in our examples, be reversed by, a 'positive' strategy?

3 Tradução do livro do ingles: "racialized regime of representation"

4 Tradução do livro do inglês: "meaning ‘floats'. It cannot be finally fixed"
} 
preferido?5" naquele suporte da informação e qual deles vamos privilegiar?

Além disso, há um anseio dos movimentos negros em privilegiar imagens e ações positivas de negras e negros na publicidade, com isso elevando a autoestima e autoimagem desta parcela da população, porém deve-se ter o cuidado de não cair na armadilha do "estereótipo do outro6", pois segundo Hall (1997, p.274) “A estratégia desafia, contesta os binários - mas não os mina. O rastafári amante da paz e dedicado às crianças pode aparecer mais vezes, no jornal do dia seguinte, como um estereótipo negro exótico e violento...”"

Esta é a luta pela representação da "diferença", que está intrinsecamente ligada às relações de poder e parece estar longe de se extinguir. Acredita-se que um dos caminhos para desconstruir este imaginário negativo das mulheres negras, legitimado durante séculos se dá por meio da educação, da visibilidade positiva e do protagonismo de negras e negros nos inúmeros dispositivos comunicacionais que se tem à disposição.

\section{CONSIDERAÇÕES FINAIS}

A exclusão e estereotipização da figura feminina negra em construções publicitárias podem provocar crises de aceitação nas afrodescendentes, além de ser objeto gerador de doenças sociais adquiridas em situações desfavoráveis, como transtorno mental e depressão. É fato que as mulheres negras estão em desvantagem social no Brasil. Entretanto, elas existem, e em grande quantidade. Renegando essa realidade, o discurso publicitário acostumou-se a destinar espaços e posições subalternas para as negras. É dessa forma que a publicidade, bem como a mídia hegemônica, reproduz desigualdades e legitima valores deturpados da vida social.

Os meios de comunicação nacionais reforçam a identidade racial negativa do negro, alimentando simbolicamente o ideal de branqueamento, sendo uma de suas consequências o desejo de euro-

5 Tradução do livro do inglês: "Which is the preferred meaning?"

6 Tradução do livro do inglês: "stereotypical other"

7 Tradução do livro do ingles: "The strategy challenges the binaries - but it does not undermine them. The peace-loving, child-caring Rastafarian can still appear, in the following day's newspaper, as na exotic and violent Black stereotype..." 
norte-americanização que faz com que, mesmo após cem anos do movimento eugenista, que iniciou no final do século XIX, negros e negras permaneçam com as mesmas compulsões desagregadoras de uma auto-imagem depreciativa. (SANTOS, 2004, p.10)

Cabe frisar, que o presente estudo optou por não analisar anúncios ou campanhas especificas de uma marca ou publicação, nem fazer cálculos quantitativos da presença de mulheres negras na publicidade brasileira. As imagens foram escolhidas a partir da busca pelo que o setor publicitário vem produzindo de uma forma geral e, é claro, que contassem com a participação das afrodescendentes. Outro ponto a se ressaltar: apesar da presença da mulher negra na publicidade ser o objeto deste estudo, especialmente em sua fase adulta, não podemos esquecer que os homens negros, assim como as crianças negras também não vivem em um ambiente de democracia midiática. Dito isso, o artigo pretende agregar e continuar reflexões aos outros estudos que foram produzidos nos últimos anos com esta temática.

\section{REFERÊNCIAS}

BONADIO, As modelos negras na publicidade de moda no Brasil dos anos 1960. Maria Claudia. Visualidades - Revista do Programa de Mestrado em Cultura Visual. Faculdade de Artes Visuais. Universidade Federal de Goiás. 2009.

BORGES, Rosane da Silva. Mídia, racismos e representações do outro: ligeiras reflexões em torno da imagem da mulher negra. In: BORGES, Roberto Carlos da Silva; BORGES, Rosane (Orgs.). Coleção Negras e Negros: Pesquisas e Debates. Coordenação: Tânia Maria Pedroso Müller. Petrópolis, RJ: DP ET Alii. Brasília, DF: ABPN, 2012. p. 178-203.

CASTRO, Ana Lúcia de. Cultura contemporânea, identidades e sociabilidades - olhares sobre o corpo, mídia e novas tecnologias. São Paulo. Cultura Acadêmica. 2010.

CORRÊA, L. G. De corpo presente: o negro na publicidade em revista. 2006. Dissertação (Mestrado em Comunicação Social) - Universidade Federal de Minas Gerais, 2006.

COUTINHO, Cassi Ladi Reis. A Estética e o mercado produtor-consumidor de beleza e cultura. 2011.

FRY, Peter. A persistência da raça: ensaios antropológicos sobre o Brasil e a África austral. 2005.

GIACOMINI, Gino. Consumidor versus propaganda. São Paulo. Summus. 1991.

HALL, Stuart. The work of representation. In: HALL, Stuart (org.) Representation. Cultural Representation and Signifyng Pratices. Sage/Open University: London/New Delhi, 1997. 
LOPES, Nei. O racismo: explicado aos meus filhos. Rio de Janeiro. Agir. 2007.

MARTINS, Carlos Augusto de Miranda e. Racismo anunciado: o negro e a publicidade no Brasil. Dissertação (Ciências da Comunicação) - Universidade de São Paulo. 2009.

PIRES, R. O negro como modelo publicitário. Revista Propaganda, São Paulo, n. 40, p. 10-18. 1988.

RAMOS, Sílvia. Mídia e racismo. Rio de Janeiro. Pallas. 2002.

WILLIAMS, Raymond. Marxismo e literatura. Rio de Janeiro: Zahar, 1979.

RECH, Claudio Moser Daniel. Direitos humanos no Brasil: diagnostico e perspectivas. Rio de Janeiro. Mauad. 2003.

SANTOS, João Batista Nascimento do. O negro representado na revista Raça Brasil: a estratégia de identidade na mídia étnica. Dissertação (Mestrado em Comunicação e Informação) - Universidade Federal do Rio Grande do Sul. 2004.

SCHWARCZ, Lilia Moritz. Retrato em branco e negro: jornais, escravos e cidadania em São Paulo ao final do século XIX. São Paulo. Cia das Letras. 2001.

\section{Sites Consultados}

http://www.casperlibero.edu.br/noticias/index.php/2009/09/25/historia-da-publicidade, $\mathrm{n}=1564 . \mathrm{html}$

http://www.itaucultural.org.br/aplicexternas/enciclopedia_teatro/index.cfm?fuseaction=cias_biografia\&cd_verbete $=649$

http://www1.folha.uol.com.br/colunas/keilajimenez/1104759-camila-pitanga-e-a-rainha-doscomerciais.shtml

http://casadecriadores.uol.com.br/2011/05/negro-e-lindo-as-principais-modelos-negras-da -historia-da-moda/

http://www.ecodebate.com.br/2010/05/25/pesquisa-identifica-que-mulheres-negras-sao-as -principais-vitimas-de-violencia-no-rio-de-janeiro/

RECEBIDO EM: 28/11/13

ACEITO PARA PUBLICAÇÃO: 18/12/12 


\section{Rafael Rangel Winch}

Graduando em Comunicação Social (Jornalismo) pela Universidade Federal de Santa Maria. Bolsista do PET Comunicação Social pela mesma instituição. Membro do programa Ecolândia - O Mundo Onde A Gente Vive, transmitido na rádio comunitária Caraí FM de Santa Maria. Participa do Grupo de Estudos de Jornalismo, com ênfase na Análise do discurso.

\section{Giane Vargas Escobar}

Doutoranda pelo Programa de Pós-Graduação em Comunicação Midiática da Universidade Federal de Santa Maria (UFSM) - Linha de Pesquisa Mídia e Identidades Contemporâneas (2012). Mestre em Patrimônio Cultural pela UFSM (2010). Especialista em Museologia pelo Centro Universitário Franciscano/UNIFRA (2002). Graduada em Letras pela Faculdade de Filosofia, Ciencias e Letras Imaculada Conceicão/FIC (1988). Responsável pelo Projeto Museológico de criação e revitalização do Museu Treze de Maio, o primeiro museu da cultura afro-brasileira do estado do RS, sendo a sua atual Diretora Técnica. Coordenadora Executiva do projeto Portal para os Clubes Sociais Negros dos Brasil desde 2009. Membro do Grupo de Estudos Culturais e Audiovisualidades do Curso de Comunicação da UFSM, coordenado pela Profa Dra. Ana Coiro e Prof. Dr. Flavi Lisboa. 